УДК 663.253 .4

DOI 10.30679/2219-5335-2019-1-55-144-152

ОСОБЕННОСТИ

ИЗМЕНЕНИЯ ЭКСТРАКТИВНОСТИ

И ДЕГУСТАЦИОННОЙ ОЦЕНКИ

ВИНОМАТЕРИАЛОВ

ПОД ДЕЙСТВИЕМ РАЗЛИЧНЫХ АГРОТЕХНИЧЕСКИХ ПРИЕМОВ

Якименко Елена Николаевна

канд. с.-х. наук

старший научный сотрудник

НЦ «Виноделие»

Агеева Наталья Михайловна

д-р техн. наук, профессор

главный научный сотрудник

НЦ «Виноделие»

Петров Валерий Семенович

д-р с.-х. наук

зав. функциональным научным центром

«Виноградарство и виноделие»

Бирюкова Светлана Александровна аспирант

Михеев Евгений Михайлович аспирант

Федеральное государственное бюджетное научное учреждение «Северо-Кавказский федеральный научный центр садоводства, виноградарства, виноделия», Краснодар, Россия

Качество экстракта является одним из важнейших показателей вин различных типов. Его содержание в вине обусловливается компонентами винограда и продуктами жизнедеятельности винных дрожжей. Концентрация экстрактивных компонентов винограда зависит от сорта, условий его произрастания, агротехнологии выращивания.

Установлено изменение массовой концентрации экстрактивных соединений и дегустационной оценки белых и красных столовых виноматериалов в зависимости от содержания почвы, нагрузки виноградных кустов урожаем, применения
UDC 663. 663.253.4

DOI 10.30679/2219-5335-2019-1-55-144-152

\section{FEATURES OF CHANGE OF EXTRACTING AND TESTING OF WINEMAKING MATERIALS UNDER THE INFLUENCE OF DIFFERENT AGROTECHNICAL METHODS}

Yakimenko Elena Nikolaevna

Cand. Agr. Sci.

Senior Research Associate of SC «Wine-making»

Ageyeva Natalia Mikhaylovna

Dr. Sci. Tech., Professor

Chief Research Associate

of SC «Wine-making»

Petrov Valeriy Semioynovih

Dr. Sci. Agr.

Head of the Functional Scientific Center of «Viticulture and Wine-making»

Biryukova Svetlana Aleksandrovna Post graduate Student

Mikheyev Evgeniy Mikhailovich

Post graduate Student

Federal State Budget

Scientific Institution

"North Caucasian Federal

Scientific Center of Horticulture,

Viticulture, Wine-making»,

Krasnodar, Russia

Quality of extract is one of the most important indicator of the wines of different types. Its content in the wine depends on the grape components and the products of the wine yeast vital activity. The concentration of the extractive grape components depends on the variety, the conditions of its growth and agrotechnology of cultivation. It is established a change in the mass concentration of extractive substances and testing estimation of white and red table wine materials depending on the soil maintenance, the load of grape bushes by harvest, 
антитранспирантов, экспозиции склонов и использованных для изготовления виноматериала частей грозди. В наших исследованиях на сорте винограда Шардоне показано, что при задернении почвы, в сравнении с контролем - черным паром, количество экстракта снижалось на 12-15\%, при обработке винограда антитранспирантами - на $12 \%$, при выращивании винограда только на южном склоне - на $9 \%$.

В виноматериалах из винограда сорта Каберне-Совиньон показатель приведенного экстракта увеличивался как при задернении (в 1,1-1,4 раза), так и при изменении нагрузки (в 1,1-1,2 раза). На южных склонах этот показатель также был выше, чем в контрольном варианте и на северных склонах (26,1 мг/дм ${ }^{3}$ против 23,1 мг/дм³ $)$.

На дегустационную оценку виноматериалов сорта Шардоне наибольшее положительное влияние оказали обработки винограда антитранспирантом Вапор Гард, а также повышение нагрузки кустов. Задернение почвы увеличило кислотность виноматериала и снизило его дегустационную оценку. Применение задернения, антитранспиранта Вапор Гард, а также размещение кустов на южном склоне привело к улучшению органолептических достоинств виноматериалов из сорта винограда Каберне-Совиньон.

Ключевые слова: ЭКСТРАКТ, ДЕГУСТАЦИОННАЯ ОЦЕНКА, ВИНОМАТЕРИАЛ, ЗАДЕРНЕНИЕ, НАГРУЗКА, АНТИТРАНСПИРАНТ the application of antitranspirants, the exposure of slopes and parts of the bunches used for wine materials. It is shown in our research that for Chardon grapes the turfing of soil in the comparison with the control -«black vapor soil» - a quantity of the extract was lowered on 12-15\%, with processing of grapes by antitranspirant - on $12 \%$, with the cultivation of grapes only on the Southern slope - on $9 \%$. In wine material from the Cabernet-Sovinon grapes the index of the extract increased both with soil turfing (by 1,1-1,4 time) and with a change in the load (by 1,1-1,2 times). This index was also higher on the Southern slopes, than that for the control version and for the Northern slopes $\left(26,1 \mathrm{mg} / \mathrm{dm}^{3}\right.$ against $\left.23,1 \mathrm{mg} / \mathrm{dm}^{3}\right)$. For the testing estimation of Chardon wine material the greatest positive influence was shown in the case of grapes processing by Vapor Gard antitranspirant as well the increase in the load of bush. The soil turfing led to an increase in wine material acidity and reduction in its testing estimation. The use of soil turfing, and Vapor Gard antitranspirant as well as the arrangement of bushes on the Southern slope led to an improvement in the organoleptic merits of wine materials from Cabernet-Sovinon grapes.

Key words: EXTRACT, TESTING ESTIMATION, WINE MATERIAL, TURFING, LOAD, ANTITRANSPIRANT

Введение. Экстракт вина, сумма всех содержащихся в вине нелетучих веществ, один из важных показателей качества, позволяющий судить о полноте вкусовых достоинств вина, гармонии вкуса, о величине антиоксидантной активности и даже о подлинности происхождения винной продукции [1-7]. Различают общий и приведённый экстракт. Общий экстракт вина представляет собой суммарную концентрацию всех растворенных в 
Плодоводство и виноградарство Юга России № 55(01), 2019 г.

вине нелетучих веществ, включая углеводы, глицерин, нелетучие кислоты, азотистые соединения, дубильные и красящие вещества, высшие спирты, минеральные вещества $[8,9]$. Приведённый экстракт - это общий экстракт вина за вычетом концентрации восстанавливающихся сахаров.

Содержание экстрактивных компонентов в вине зависит от сорта винограда, почвенно-климатических и метеорологических условий его произрастания, степени зрелости ягод и способа их переработки, условий брожения, типа вина [10-13]. В белых сухих винах содержание приведенного экстракта в среднем составляет 22 г/дм³; в красных сухих винах, более экстрактивных - до 30 г/дм³ [14-16].

Однако изменяющиеся условия выращивания винограда, агротехнологии, способы ведения почвы приводят к существенному варьированию количества как отдельных экстрактивных компонентов - сахаров, полисахаридов, дубильных и красящих веществ, так и общего экстракта в целом. При этом можно отметить, что различные технологии выращивания винограда поразному влияют на концентрации экстрактивных веществ. В связи с этим, цель работы - установить изменение концентрации экстракта и дегустационной оценки вин под действием различных агротехнических приемов.

Объекты и методы исследований. В качестве объектов исследований использовали белые и красные столовые виноматериалы, произведенные из винограда сортов Шардоне и Каберне-Совиньон, выращенных в ЗАО «Скалистый берег» Анапского района Краснодарского края. Схема опыта представлена на рис. 1.

Из винограда исследуемых сортов по общепринятым технологиям в одинаковых условиях брожения были приготовлены опытные образцы натуральных столовых вин. По физико-химическим показателям все образцы соответствовали требованиям нормативной документации [17]. Массовую концентрацию приведенного экстракта в экспериментальных варинтах определяли по существующему методу [18]. Органолептические 
Плодоводство и виноградарство Юга России № 55(01), 2019 г.

свойства оценивала дегустационная комиссия СКФНЦСВВ по десятибалльной системе.

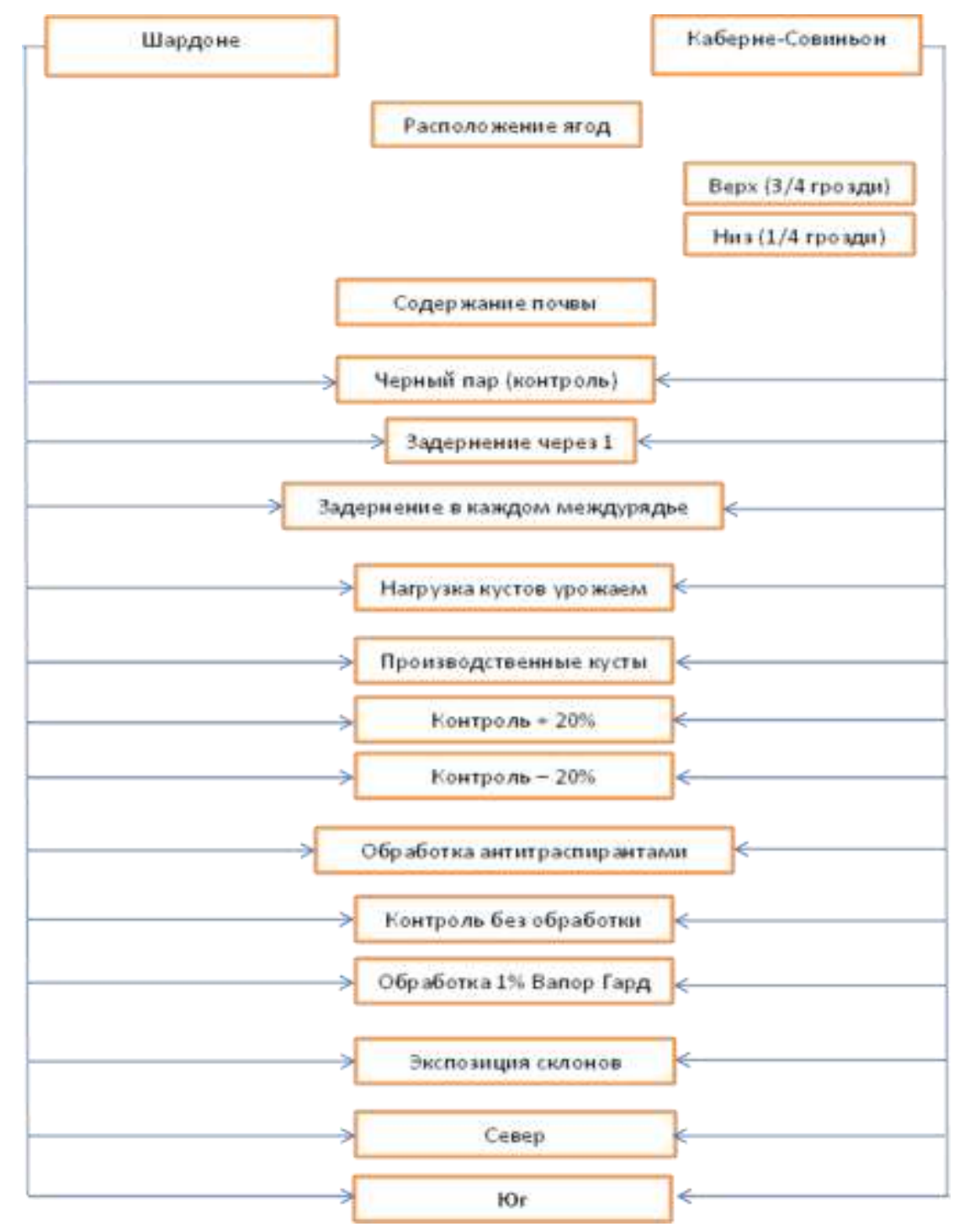

Рис. 1. Схема опыта (ЗАО «Скалистый берег», 2017 г.)

Обсужнение результатов. Анализируя полученные результаты, можно отметить существенное варьирование массовой концентрации экстракта в зависимости от приемов агротехнологии и сорта винограда. Определено, что в виноматериалах из сорта винограда Шардоне наибольшая концентрация экстракта была в контрольных вариантах. При задернении почвы виноградника его количество снижалось на 12-15 \%: при обработке винограда антитранспирантом - на 12 \%, при выращивании винограда только на южном склоне - на 9 \%. Снижение нагрузки кустов урожаем 
привело к увеличению концентрации экстракта, а увеличение нагрузки к уменьшению количества экстрактивных соединений (рис. 2), что в целом, согласуется с имеющимися литературными данными [19-21].

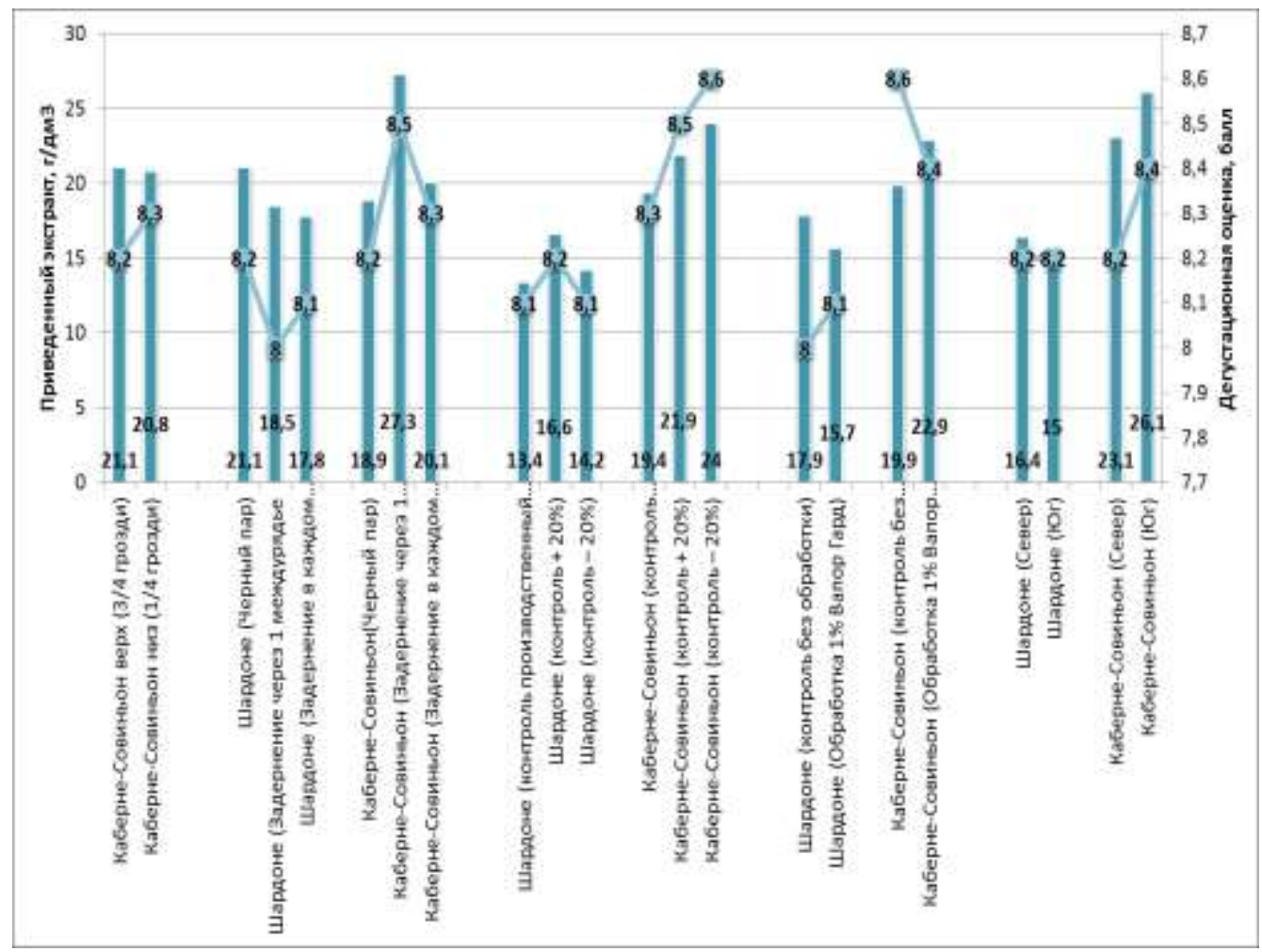

Рис. 2. Массовая концентрация приведенного экстракта и дегустационная оценка столовых сухих виноматериалов из винограда сортов Шардоне и Каберне-Совиньон (ЗАО «Скалистый берег», 2017 г.)

В виноматериалах из винограда сорта Каберне-Совиньон показатель приведенного экстракта увеличивался как при задернении (в 1,1-1,4 раза), так и при изменении нагрузки (в 1,1-1,2 раза). На южных склонах этот показатель также был выше. чем в контрольном варианте и на северных склонах (26,1 мг/дм³ против 23,1 мг/дм³). При исследовании экстрактивности виноматериалов, приготовленных из различных частей грозди (верхняя, нижняя), были получены близкие результаты. Между тем, следует отметить, что все же экстрактивность виноматериала, приготовленных из ягод верхней части грозди, была несколько выше (см. рис. 2).

Дегустационной комиссией СКФНЦСВВ были оценены органолептические свойства выработанных столовых виноматериалов из исследуемых 
сортов винограда. Примененные агротехнические приемы оказали различное влияние на дегустационную оценку виноматериалов, при этом исследуемые сорта винограда по-разному отреагировали на задернение почвы.

Дегустационная оценка виноматериалов из винограда сорта Шардоне снизилась по сравнению с контролем (черный пар) на 0,1-0,2 балла и составила 8,0 (задернение через ряд) и 8,1 балла (задернение в каждом междурядье). Контрольный виноматериал обладал светло-соломенным цветом, ярким, цветочным, с оттенками полевых трав, слаженным ароматом, полным, умеренно свежим, чистым вкусом. В виноматериалах варианта опыта с задернением вкус был более свежим. При повышении нагрузки куста урожаем дегустационная оценка также повысилась на 0,1 балла.

Благоприятно на органолептические свойства сказалась обработка винограда антитранспирантом. Виноматериал был оценен на 8,1 балла и выделялся светло-соломенным цветом, ярким, цветочно-плодовым ароматом и полным, умеренно свежим, округлым вкусом. Экспозиция склона не повлияла на органолептические свойства и дегустационную оценку виноматериалов из винограда сорта Шардоне (см. рис. 2).

Опытные варианты виноматериалов из винограда сорта КабернеСовиньон были оценены выше, чем контрольные. При задернении междурядий и при изменении нагрузки кустов урожаем дегустационная оценка достигала 8,3-8,6 балла, против контроля 8,1-8,2 балла на контроле. Виноматериалы отличались интенсивным темно-рубиновым цветом, ярким, сложным, ягодным ароматом, с оттенками фиалки и пиона, полным, умеренно свежим, танинным вкусом.

Размещение кустов винограда на южном склоне положительно сказалось на органолептических свойствах образцов - дегустационная оценка повысилась на 0,2 балла по сравнению с вариантом размещения кустов на северном склоне (см. рис. 2).

Дегустационная оценка виноматериалов из сорта Каберне-Совиньон снизилась только в опыте с использованием антитранспиранта, контроль без 
Плодоводство и виноградарство Юга России № 55(01), 2019 г.

обработки получил один из высоких баллов - 8,6. Он обладал темнорубиновым цветом, ярким, сложным, ягодным ароматом, с оттенками паслена и чернослива, полным, умеренно свежим, бархатистым вкусом. Выращивание винограда на южном склоне также положительно повлияло на органолептические свойства и дегустационный балл виноматериалов из винограда сорта Каберне-Совиньон. Образец обладал темно-рубиновой окраской, ярким, сложным, ягодным, с оттенками паслена и терна ароматом, полным, умеренно свежим, бархатистым вкусом и был оценен на 8,4 балла.

Bbыводы. Установлено достоверное положительное влияние агротехнических приемов (задернение, применение антитранспирантов, экспозиция склона) на массовую концентрацию приведенного экстракта и, как следствие, улучшение органолептических свойств виноматериалов из винограда сорта Каберне-Совиньон.

\section{Литература}

1. Letenneur, L., Larrieu, S., Helmer, C., Dartigues, J. F., \& Barberger-Gateau, P. (2004). Nutritional factors and risk of incident dementia in the PAQUID longitudinal cohort. The Journal of Nutrition, Health \& Aging, 8(3), 150-154.

2. Charters M.A., M.W. Wine and Society The Social and Cultural Context of a Drink. - 2006 Elsevier Ltd 2. Galet, P. Dictionnaire encycloperdique des cer pages / P. Galet Hachette, 2000. - 936 p.

3. Dallas C., Laureano O. Effect of SO2 on the extraction ofin dividual anthocyanins and colored matter of three Portuguese grape varieties during winemaking // Vitis. 1994 V. 33 P. 41-47.

4. Durakova, A.G., A.L. Bogoeva, A.I. Pavlov, K.T. Dinkov, R.Z. Vrancheva and V.B. Yanakieva, 2018. Antioxidant activity and storage regime of grape seeds flakes -a waste product in wine elaboration. Bulg. J. Agric. Sci., 24 (3): 503-508

5. Панасюк А.Л., Бабаева М.И. Критерии качества белых вин Нового Света // Виноделие и виноградарство. - 2013. - № 5. - С. 22-24.

6. Агеева Н.М., Гугучкина Т.И. Идентификация и экспертиза виноградных вин и коньяков. - Краснодар: ГНУ СКЗНИИСиВ; 2008. - 174 с.

7. Гугучкина Т.И., Якуба Ю.Ф., Бирюкова С.А. Особенности выявления подлинности виноградных вин с помощью органических и фенолкарбоновых кислот // Научные труды СКФНЦСВВ. Том. 18. - Краснодар: СКФНЦСВВ, 2018. - С. 190-193.

8. Агеева Н.М., Прах А.В., Бирюкова С.А. Исследование фенольных соединений красных столовых виноматериалов, произведённых из различных сортов винограда // Научные труды СКФНЦСВВ. Том. 15. - Краснодар: СКФНЦСВВ, 2018. - С. 135-140.

9. Mridula Chopra, Patricia E.E. Fitzsimons, John J. Strain, David . Thurnham, and Alan N. Howard Nonalcoholic Red Wine Extract and Quercetin Inhibit LDL Oxidation without Affecting Plasma Antioxidant Vitamin and Carotenoid Concentrations. Clinical Chemistry 46:8 1162-1170 (2000). 
10. Rapcea M., Nedealcov M. Fundamentarea dezvoltării durabile a viticulturii în dependenţă de climă. Chisinau, 2014, p. 212. ISBN 978-9975-62-378-0

11. Петров В.С., Гугучкина Т.И., Алейникова Г.Ю., Чекмарева М.Г. Влияние разных способов содержания почвы на качество натуральных сухих виноматериалов из сортов Выдвиженец и Бианка // Виноделие и виноградарство. - 2005. - № 4. - С. 15-17.

12. Петров В.С., Гугучкина Т.И., Антоненко М.В., Лукьянов А.А. Влияние биологизированных систем содержания почвы на качество виноматериалов из сорта Бианка // Виноделие и виноградарство. - 2009. - № 4. - С. 36-39.

13. Лукьянов А.А., Дергунов А.В. Влияние почвенной составляющей терруара анапского региона на продуктивность и качество вина сорта Каберне Совиньон [Электронный ресурс] // Плодоводство и виноградарство Юга России. 2018. № 54(6). C. 72-82. URL: http://journalkubansad.ru/pdf/18/06/08.pdf. DOI: 10.30679/2219-5335-20186-54-72-82 (дата обращения: 30.11.2018).

14. Аношин И.М., Мержаниан А.А. Физические процессы виноделия. Москва: Пищевая промышленность, 1976. -375 с.

15. Richard Draijer, Young de Graaf, Marieke Slettenaar, Eric de Groot and Chris I. Wright. Consumption of a Polyphenol-Rich Grape-Wine Extract Lowers. Ambulatory Blood Pressure in Mildly Hypertensive Subjects. - Nutrients 2015, 7, 3138-3153;

16. Ough C. Substances Extracted during Skin Contact with White Musts. General Wine Composition and Quality Changes with Contact Time.-American Journal Enology and Viticulture. - 2008. - 260.

17. ГОСТ 32030-2013 «Вина столовые и виноматериалы столовые. Общие технические условия. Продукция алкогольная и сырье для ее производства». - Дата введения 2014-07-01. - М.: Стандартинформ, 2014. - 7 с.

18. ГОСТ 32000-2012 «Продукция алкогольная и сырье для ее производства. Метод определения массовой концентрации приведенного экстракта». - Введ. 01.07.2014. - М.: Стандартинформ, 2014. -6 с.

19. Biochemical and agronomical responses of grapevinesto alteration of source-sink ratio by cluster thinning and shoot trimming/ da MotaR.V., de Souza C.R., Silva C.P.C., Regina M.D.A., Freitas G.D.F., Shiga T.M., Purgatto E., Lajolo F.M., Bragantia. 2010. T. 69. № 1. S. 17-25.

20. Foroni, F. The smell of terroir! Olfactory discrimination between wines of different grape variety and different terroir / F. Foroni and el. // Food Quality and Preference. 2017. - V. 58. - P. 18-23.

21. Лукьянов А.А., Антоненко М.В., Гапоненко Ю.В., Гонтарева Е.Н. Влияние факторов среды ампелоценоза на формирование качественных показателей вина // Политематический сетевой электронный научный журнал Кубанского государственного аграрного университета. - 2015. - № 112. - С. 1224-1235.

\section{References}

1. Letenneur L., Larrieu, S., Helmer C., DartiguesJ. F., \& Barberger-Gateau P. (2004). Nutritional factors and risk of incident dementia in the PAQUID longitudinal cohort. The Journal of Nutrition, Health \& Aging, 8(3), 150-154.

2. Charters M.A., M.W. Wine and Society The Social and Cultural Context of a Drink. - 2006 Elsevier Ltd 2. Galet, P. Dictionnaire encycloperdique des cer pages / P. Galet Hachette, 2000. - 936 p.

3. Dallas C., Laureano O. Effect of SO2 on the extraction ofin dividual anthocyanins and colored matter of three Portuguese grape varieties during winemaking // Vitis. 1994 V. 33 P. 41-47.

4. Durakova, A.G., A.L. Bogoeva, A.I. Pavlov, K.T. Dinkov, R.Z. Vrancheva and V.B. Yanakieva, 2018. Antioxidant activity and storage regime of grape seeds flakes -a waste product in wine elaboration. Bulg. J. Agric. Sci., 24 (3): 503-508 
5. Panasyuk A.L., Babaeva M.I. Kriterii kachestva belyh vin Novogo Sveta // Vinodelie i vinogradarstvo. - 2013. - № 5. - S. 22-24.

6. Ageeva N.M., Guguchkina T.I. Identifikaciya i ekspertiza vinogradnyh vin i kon'yakov. - Krasnodar: GNU SKZNIISiV; 2008. - 174 s.

7. Guguchkina T.I., Yakuba Yu.F., Biryukova S.A. Osobennosti vyyavleniya podlinnosti vinogradnyh vin s pomoshch'yu organicheskih i fenolkarbonovyh kislot // Nauchnye trudy SKFNCSVV. Tom. 18. - Krasnodar: SKFNCSVV, 2018. - S. 190-193.

8. Ageeva N.M., Prah A.V., Biryukova S.A. Issledovanie fenol'nyh soedinenij krasnyh stolovyh vinomaterialov, proizvedyonnyh iz razlichnyh sortov vinograda // Nauchnye trudy SKFNCSVV. Tom. 15. - Krasnodar: SKFNCSVV, 2018. - S. 135-140.

9. Mridula Chopra, Patricia E.E. Fitzsimons, John J. Strain, David . Thurnham, and Alan N. Howard Nonalcoholic Red Wine Extract and Quercetin Inhibit LDL Oxidation without Affecting Plasma Antioxidant Vitamin and Carotenoid Concentrations. Clinical Chemistry 46:8 1162-1170 (2000).

10. Rapcea M., Nedealcov M. Fundamentarea dezvoltării durabile a viticulturii în dependenţă de climă. Chisinau, 2014, p. 212. ISBN 978-9975-62-378-0

11. Petrov V.S., Guguchkina T.I., Alejnikova G.Yu., Chekmareva M.G. Vliyanie raznyh sposobov soderzhaniya pochvy na kachestvo natural'nyh suhih vinomaterialov iz sortov Vydvizhenec i Bianka // Vinodelie i vinogradarstvo. - 2005. - № 4. - S. 15-17.

12. Petrov V.S., Guguchkina T.I., Antonenko M.V., Luk'yanov A.A. Vliyanie biologizirovannyh sistem soderzhaniya pochvy na kachestvo vinomaterialov iz sorta Bianka // Vinodelie i vinogradarstvo. - 2009. - № 4. - S. 36-39.

13. Luk'yanov A.A., Dergunov A.V. Vliyanie pochvennoj sostavlyayushchej terruara anapskogo regiona na produktivnost' i kachestvo vina sorta Kaberne Sovin'on [Elektronnyj resurs] // Plodovodstvo i vinogradarstvo Yuga Rossii. 2018. № 54(6). S. 72-82. URL: http://journalkubansad.ru/pdf/18/06/08.pdf. DOI: 10.30679/2219-5335-2018-6-54-72-82 (data obrashcheniya: 30.11.2018).

14. Anoshin I.M., Merzhanian A.A. Fizicheskie processy vinodeliya. - Moskva: Pishchevaya promyshlennost', 1976. - 375 s.

15. Richard Draijer, Young de Graaf, Marieke Slettenaar, Eric de Groot and Chris I. Wright. Consumption of a Polyphenol-Rich Grape-Wine Extract Lowers. Ambulatory Blood Pressure in Mildly Hypertensive Subjects. - Nutrients 2015, 7, 3138-3153;

16. Ough C. Substances Extracted during Skin Contact with White Musts. General Wine Composition and Quality Changes with Contact Time.-American Journal Enology and Viticulture. - 2008. - 260.

17. GOST 32030-2013 «Vina stolovye i vinomaterialy stolovye. Obshchie tekhnicheskie usloviya. Produkciya alkogol'naya i syr'e dlya ee proizvodstva». - Data vvedeniya 2014-07-01. - M.: Standartinform, 2014. - 7 s.

18. GOST 32000-2012 «Produkciya alkogol'naya i syr'e dlya ee proizvodstva. Metod opredeleniya massovoj koncentracii privedennogo ekstrakta». - Vved. 01.07.2014. - M.: Standartinform, 2014. $-6 \mathrm{~s}$.

19. Biochemical and agronomical responses of grapevinesto alteration of source-sink ratio by cluster thinning and shoot trimming / da Mota R.V., de Souza C.R., Silva C.P.C., Regina M.D.A., Freitas G.D.F., Shiga T.M., Purgatto E., Lajolo F.M., Bragantia. 2010. T. 69. № 1. S. 17-25.

20. Foroni, F. The smell of terroir! Olfactory discrimination between wines of different grape variety and different terroir / F. Foroni and el. // Food Quality and Preference. 2017. - V. 58. - P. 18-23.

21. Luk'yanov A.A., Antonenko M.V., Gaponenko Yu.V., Gontareva E.N. Vliyanie faktorov sredy ampelocenoza na formirovanie kachestvennyh pokazatelej vina // Politematicheskij setevoj elektronnyj nauchnyj zhurnal Kubanskogo gosudarstvennogo agrarnogo universiteta. - 2015. - № 112. - S. 1224-1235. 